\title{
Opportunities and challenges
} CrossMark in the development of Cutaneotrichosporon
oleaginosus ATCC 20509 as a new cell factory
for custom tailored microbial oils

\author{
Felix Bracharz ${ }^{1}$, Teun Beukhout ${ }^{2}$, Norbert Mehlmer ${ }^{1}$ and Thomas Brück ${ }^{1^{*}}$
}

\begin{abstract}
Cutaneotrichosporon oleaginosus ATCC 20509, previously known as Trichosporon oleaginosus, Cryptococcus curvatus, Apiotrichum curvatum or Candida curvata D is an oleaginous yeast with several favorable qualities: it is fast growing, accumulates high amounts of lipid and has a very broad substrate spectrum. Its resistance to hydrolysis byproducts and genetic accessibility make it a promising cell factory for custom tailored microbial oils. However, literature about this organism is of varying degree of quality. Moreover, due to numerous changes of the species name, reports are highly scattered and poorly cited. This led to a poor integration of the findings into a unified body of knowledge. Particularly, errors in strain name usage and consequently citation are found even in most recent literature. To simplify future work, this review provides an overview of published studies and main findings regarding the metabolic capacities of C. oleaginosus.
\end{abstract}

Keywords: Apiotrichum curvatum, Trichosporon oleaginosus, Cryptococcus curvatus, Cutaneotrichosporon oleaginosus, Oleaginous yeast, Single cell oil, Lipid, Basidiomycete

\section{Introduction \\ Background}

The oleaginous yeast Cutaneotrichosporon oleaginosus was originally isolated from factory drains of the Iowa State University Dairy Farm [1]. The organism can metabolize various carbohydrates including lactose and has the ability to accumulate high amounts of intracellular lipids. Although it was first deposited under the name Candida curvata $\mathrm{D}$ at the American Type Culture Collection (ATCC 20509), it has been published under various names including Apiotrichum curvatum [2], Cryptococcus curvatus [3], Trichosporon cutaneum [4] and Trichosporon oleaginosus [5]. Even though, the latter name $T$. oleaginosus has been most frequently used, the diverse designation of the species makes the quantitative

\footnotetext{
*Correspondence: brueck@tum.de

${ }^{1}$ Technische Universität München, Division of Industrial Biocatalysis,

Lichtenbergstraße 4, 85748 Garching, Germany

Full list of author information is available at the end of the article
}

acquisition of information difficult. Recently, the review of Yaguchi et al. [6], made an excellent effort to summarize and contrast the data for the prominent oleaginous yeasts C. oleaginosus and Debaryomyces hansenii. This review aims to further extend on available data of C. oleaginosus to provide the reader a comprehensive but focused overview of the metabolic capacity of this intriguing organism, which most recently has been rendered genetically accessible [7]. More generally, C. oleaginosus grows on a variety of complex biomass hydrolysates and even in the presence on fermentation inhibitors. Moreover, it has the ability of accumulate high intracellular concentrations of lipids under specific culture conditions. The cumulative genetic and biochemical features of this organism positions C. oleaginosus as a prime candidate to realize ecologically and economically sustainable single cell oil production targeted at generation of biofuels and high value oleo-chemicals. 
In a first instance, assembly of available data reports on C. oleaginosus requires a delineation of the variable taxonomic classifications for this organism.

Based on a multi-gene sequencing analysis, the phylogeny of the genus Trichosporon was recently revised [8]. Together with previous data $[9,10]$, this comprehensive multi-gene dataset lead to a taxonomic revision of the genus. More recently, a phylogenomic study encompassing genomic information of 17 species also revealed phylogenetic heterogeneity of the genus [11]. Therefore, the previous genus Trichosporon is relocated in the order of Trichosporonales now comprising of Trichosporon sensu stricto, Apiotrichum, Cutaneotrichosporon, Effuseotrichosporon, Haglerozyma, and Vanrija respectively [8]. In the course of phylogenetic restructuring, T. oleaginosus [12] was placed in the genus Cutaneotrichosporon, and renamed in C. oleaginosus [13].

The novel genius Cutaneotrichosporon actually contains now 13 species and half of them have been found grown either as pathogens or opportunist on humans. The most recent $C$. oleaginosus literature extracted in this review focuses on biotechnological aspects. Another recently published review article mainly compares $C$. oleaginosus with D. hansenii [14].

The species found in the genius Cutaneotrichosporon do not form basidiocarps, do not show sexual reproduction. Moreover, the fermentation of ethanol is not observed [8]. Apart from its commonly described yeast state, C. oleaginosus also grows in filamentous form and produces arthroconidia. In nature, it presumably grows as filamentous fungus in soil and on leaf litter [15]. Oleaginicity appears to be an adaptation to strongly varying nutrient supply, which is supported by the very low maintenance energy of the yeast [2, 16, 17]. Its genome is estimated at $19.8 \mathrm{Mbp}$, having a high GC content of $61 \%$ [18]. In the following section we will elaborate on the available data that governs metabolic capacity, substrate utilization and lipogenesis of C. oleaginosus.

\section{General physiology}

\section{Biochemistry of substrate metabolism}

Cutaneotrichosporon oleaginosus is able to grow on a variety of carbon and nitrogen sources [6]. However, very little is known about the biochemistry of its metabolic potential. While, cellulase and chitinase enzyme activities have been predicted from C. oleaginosus genome annotation [18], the organism does not grow on polysaccharide based materials, such as lignocellulose and chitin [19]. This data suggests, that putative glycosylhydrolase activities are probably of intracellular relevance, i.e. for cell wall remodeling. However, $C$. oleaginosus readily metabolizes a wide range of oligo- and monomeric sugars such as cellobiose, sucrose, lactose and glucose, galactose, galacturonic acid as well as $\mathrm{N}$-acetylglycosamine respectively [20-24].

With respect to lactose utilization two lactose hydrolases have been studied [25]. To this end, C. oleaginosus harbors a highly active and specific beta-galactosidase that requires metal ions as cofactors. Additionally, a betagalactosidase activity that does not require metal-ions but has a lower activity and specificity compared to the former enzyme variant has been identified.

While Liang et al. [26] reported arabinose utilization, Meo et al. [27] demonstrated that arabinose is not used for the generation of biomass. These results suggest that C. oleaginosus is suffering from arabinose transporter deficiency [28] and/or cofactor imbalance that would enable efficient operation of the arabinose oxidoreductase pathway [29].

In general, xylose is first converted to xylulose 5-phosphate, which in turn can be directed either towards the conventional pentose pathway or the phosphoketolase pathway [30].

Both pathways yield pyruvate as the platform metabolite, which can be further utilized for cellular metabolism. Much like other oleaginous yeasts, C. oleaginosus is capable of utilizing glycerol as an efficient carbon source [31] even in the presence of industrial contaminants [32], such as volatile fatty acids (VFA) [33] and ethanol. Most interestingly, C. oleaginosus even thrives in the presence of fermentation inhibitors such as 4-hydroxymethylfurfural [26], that is generated during physicochemical pretreatment processes of complex biomass streams (see "Effects of growth inhibitors in complex biomass hydrolysates" section). Additionally, the organism is able to metabolize simple nitrogen resources such ammonium, nitrate [33] and urea [18, 34], the latter up to a concentration of $1 \mathrm{~g} / \mathrm{l}$ without growth reduction [32].

\section{Correlating nutrient preferences and distribution with lipid accumulation}

The ability of oleaginous yeasts to generate lipids is highly dependent on the efficacy of carbon source utilization and subsequent application of nutrient stressors other than C-restraints. This section highlights the C. oleaginosus metabolic capacity utilize various carbon sources and their influence on lipogenesis.

In general, lipid accumulation can be induced by limitation of specific nutrients. In $R$. toruloides, this was demonstrated for nitrogen, phosphate and sulfur starvation [35-37]. Meo [27] evaluated these limitations for C. oleaginosus by employing different C:N, C:P and C:S ratios in two phase fed batch bioreactor cultivations. In the first phase, limitation ratios of batch media were varied. By contrast, in the second phase, limitation ratios of feed were changed. In this bioreactor set-up, $\mathrm{C}: \mathrm{N}$ ratios 
of 5-20 g carbon/g nitrogen showed no significant variation. To this end, a maximal lipid content was observed at a C:N ratio of $15 \mathrm{~g} / \mathrm{g}$. Nonetheless, subsequent culture feeds indicated that $\mathrm{C}: \mathrm{N}$ ratios have a significant impact. With decreasing C:N ratio the lipid content decreased moderately. Respectively, a strong decrease between C:N $75 \mathrm{~g} / \mathrm{g}$ (48\% g/g lipids per biomass) and C/N $50 \mathrm{~g} / \mathrm{g}(21 \%$ $\mathrm{g} / \mathrm{g}$ lipid content) was observed. Data is supported by the report of Park et al. [38], whereas Ykema et al. [2] found the critical C:N ratio to be $11 \mathrm{~g} / \mathrm{g}$. Variation of $\mathrm{C} / \mathrm{S}$ or $\mathrm{C} / \mathrm{P}$ ratios of batch media had little impact on lipid content and no lipid accumulation was induced by sulfate limitation ( $\max 15 \% \mathrm{~g} / \mathrm{g}$ lipid content after feeding). Notably, a C:P ratio of $702 \mathrm{~g} / \mathrm{g}$ was sufficient for the accumulation of $40 \% \mathrm{~g} / \mathrm{g}$ lipids, but subsequent feeding required absence of phosphate for intracellular lipids to remain constant.

The reported $\mathrm{pH}$ optima for lipid yields differ significantly between $\mathrm{pH} 4.8$ [39] and 7 [33] which fits to a wide spectrum of substrates (natural, semi-defined and synthetic) and fermentation modes applied over various studies. In synthetic media, small differences in $\mathrm{pH}$ between 5 and 6 , values which are most commonly used for cultivation, have no significant effect on lipid production [27]. Most recently, growth of C. oleaginosus was shown to benefit from cultivation in a symbiotic relationship with Synecococcus elongatus in a lichen-like structure. This resulted in higher lipid productivity, viability and growth of the oleaginous yeast [40].

There is no comprehensive model capable of predicting biomass yield and lipid content for C. oleaginosus grown in arbitrary complex media. Solely relying on carbon source concentration and C:N:S:P ratio for making predictions about lipid content and yield is not sufficient, as interaction effects with other fermentation parameters, such as oxygen supply or absolute cell concentration and concentrations of media constituents, are likely to occur (see "Mechanism and regulation of lipid accumulation" section).

However, when effects of monomeric sugar utilization in the presence of nitrogen limitation was examined, batch bioreactor fermentations [27] demonstrated that the highest biomass and lipid yields can be obtained using mannose as a carbon source, followed by galactose and glucose. By contrast, equivalent experiments with xylose and arabinose resulted in significantly lower biomass and lipid yields, indicating that pentoses are less efficient to sustain growth and lipogenesis. At present, no diauxic effect between hexose sugars has been observed $[27,41]$. Most interestingly, supplying a sugar mix rather than individual sugars lead to higher substrate assimilation and maximum growth [27]. However, in the presence of mannose and glucose, galactose utilization was somewhat delayed [27]. Moreover, in the presence of glucose, xylose consumption was significantly decreased [42]. Contrasting the bioreactor data, experiments conducted in shake flasks indicate that glucose, mannose and xylose resulted in comparable intracellular triacylglyceride (TAG) contents. The maximum lipid yield was observed with glucose as substrate followed by mannose and xylose. Again, xylose and galactose resulted in lower biomass and lipid yields. In chemostat experiments with single carbon sources, xylose was the most suitable sugar to achieve a high lipid yield followed by lactose and sucrose [22]. By contrast, Görner et al. found lipid productivity with xylose to be significantly better than with glucose or $N$-acetylglucosamine, both of which were comparable [7]. This suggests a possible involvement of phosphoketolases, which would yield $1.3 \mathrm{~mol}$ acetyl-CoA (AcCoa)/100 g xylose as opposed to $1 \mathrm{~mol}$ AcCoa/100 g xylose over the pentose phosphate way. Via glycolysis, $1.1 \mathrm{~mol}$ AcCoA can be generated from 100 g glucose [30, 43]. In general, metabolic flux from lactose or xylose as carbon source to lipid appears to be less favorable [44]. This may however depend on the presence of further carbon sources and possibly cultivation conditions. The preferred nitrogen sources for lipid accumulation were asparagine and urea, which yielded a higher triglyceride content in C. oleaginosus than growth with yeast extract [32]. Most notably, if volatile fatty acids (VFAs) are used as substrate, acetic acid is not only the cheapest option, but also yields higher lipid contents in comparison to butyric acid or propionic acid [45]. Synergistic effects can improve lipid yields. This was shown by Gong et al. [46] using glucose, xylose and acetate in a co-fermentation study. Although, the presence of acetate did not change the capacity of sugar utilization, cell mass and lipid content increased over time and reached $24.5 \mathrm{~g} / \mathrm{l}$ and 59.3\% respectively. The final lipid yield reached $17.5 \mathrm{~g} / 100 \mathrm{~g}$ (C:N ratio of 72) [46].

\section{Effects of growth inhibitors in complex biomass hydrolysates}

Acid catalyzed thermochemical pretreatment or saccharification of polymeric biomass substrates, such as cereal straw and wood chips, is accompanied by the generation of fermentation inhibitors [47]. These comprise weak organic acids (acetic acid, levulinic acid), sugar derived furanes (i.e. furfural) and phenolic compounds (i.e. vanillin) originating from lignin breakdown [48]. Compared to other yeast and filamentous fungi, $C$. oleaginosus displays enhanced resistance towards these inhibitors. Therefore it grows comparatively well in a variety of non-detoxified biomass hydrolysates, which represents a significant cost advantage [49]. However, growth is significantly impaired by $1 \mathrm{~g} / \mathrm{l}$ furfural [49] or $20 \% \mathrm{w} / \mathrm{w}$ final cell dry weight $(\mathrm{CDW})$. However, at higher concentrations $\mathrm{CDW}$ 
remains constant [44]. Inhibition by hydroxymethylfurfural (HMF), $p$-hydroxybenzaldehyde (PHB) and syringaldehyde is low at $1 \mathrm{~g} / \mathrm{l}(<5 \% \mathrm{w} / \mathrm{w} \mathrm{CDW})$, whereas vanillin at the same concentration reduces CDW by $20 \%$ $\mathrm{w} / \mathrm{w}$ at $1 \mathrm{~g} / \mathrm{l}$ and $40 \% \mathrm{w} / \mathrm{w}$ at $1.5 \mathrm{~g} / \mathrm{l}$. Most notably, the impact of the former inhibitory substances have impact both CDW and the final lipid content (LC) in a similar manner. To that end, furfural reduces LC to $40 \% \mathrm{w} / \mathrm{w}$ compared to the control, while the LC reduction by PHB and syringaldehyde are below $5 \% \mathrm{w} / \mathrm{w}$. Inhibition of both growth and lipid content can depend on substrate utilization: when $C$. oleaginosus is grown on glucose, in the presence of $1 \mathrm{~g} / \mathrm{l}$ vanillin a 22\% w/w CDW and $10 \% \mathrm{w} / \mathrm{w}$ LC reduction was observed respectively. By comparison, when xylose was the main carbon source, the CDW and $\mathrm{LC}$ reductions were $30 \% \mathrm{w} / \mathrm{w} \mathrm{CDW}$ and $22 \% \mathrm{w} / \mathrm{w} \mathrm{LC}$ [44].

Volatile fatty acids, despite their general suitability as substrate, impair growth at moderate concentrations (43\% w/w CDW reduction at $5 \mathrm{~g} / \mathrm{l}$ for acetic acid) [50]. The inhibitory effect appears to be based on the accumulation of intracellular anions [51]. When using a synthetic broth of VFAs, the threshold for inhibition was found at $6 \mathrm{~g} / \mathrm{l}$ [45]. However this could be circumvented by raising initial biomass concentration. Up to $40 \mathrm{~g} / \mathrm{l} \mathrm{KAc}$, only the growth rate and lag phase, but not the final biomass yield are impaired [52]. Interestingly, glycerin concentrations beyond $20 \mathrm{~g} / \mathrm{l}$ [53] also seem to be inhibitory. Maximum growth rates decrease by 20 and $80 \%$ at glycerin concentrations of 100 and $150 \mathrm{~g} / \mathrm{l}$ respectively [32]. Moreover, an alkaline $\mathrm{pH}$ at the start of the fermentation appears to extend the lag phase of the cultivation process [52].

More generally, in the presence of inhibitors, an inoculum of $10 \% \mathrm{v} / \mathrm{v}$ of overnight culture is recommended.

\section{Cell wall composition}

From a technical perspective the chemical composition of the cell wall is crucial if enzymatic methods are to be developed for generation of spheroplasts to establish gene transfer protocols or simply for enzyme mediated cell lysis. Under non-nutrient limiting conditions, the cell wall of $C$. oleaginosus consists mostly of neutral carbohydrates $(63 \% \mathrm{w} / \mathrm{w})$. However, significant concentrations of glucosamine $(9 \% \mathrm{w} / \mathrm{w})$, glucuronic acid $(13 \% \mathrm{w} / \mathrm{w})$ and protein $(11 \% \mathrm{w} / \mathrm{w})$ are also present [15]. Nonetheless, in comparison to other yeast species, such as $S$. cerevisiae (neutral sugar content: $80-90 \% \mathrm{w} / \mathrm{w}$ ), the C. oleaginosus cell wall displays a relatively low amount of neutral carbohydrates [54, 55]. The mannose content of C. oleaginosus cell wall is significantly lower than for $S$. cerevisiae and the high content of uronic acids is unusual for fungi in general. The cell wall is susceptible to digestion by
Novozyme 234 [56], which can be exploited for transformation of genetic material.

It is reported that yeasts can accumulate large amounts of disaccharides, trehalose or polysaccharides, such as glycogen or pullulan when metabolically stressed [57]. With increasing nitrogen limitation, lipid content as well as carbohydrate content in C. oleaginosus increase [2]. However, lipid accumulation continues even in the stationary phase and is accompanied by a decrease in intracellular carbohydrates [58]. Consequently, carbon source uptake [2] does not appear to be the rate limiting step for the accumulation of lipids. Instead, the subsequent carbon flow to fatty acids (FA) and/or TAG assembly appear to be main bottleneck. This leads to accumulation of sugars in the cell, which act as a "short term" storage product [59]. So far, no qualitatively change in the cell wall sugar profile under nutrient limiting conditions has been reported. However, among the highly upregulated genes under nitrogen limiting conditions is an endoglucanase [18] (Triol1|310356), which is possibly associated with the decomposition of intracellular polysaccharides. Further studies are required to understand changes in the cell wall composition under nutrient limiting and other stress conditions and this data needs to be correlated with lipogenesis under the stress conditions applied.

\section{The fatty acid profile of the intracellular lipid fraction}

The precise fatty acid profile of intracellularly accumulated lipids is essential to determine the technical application of single cell lipids. To that end, Wei et al. [60] reported that C. oleaginosus accumulated $88 \% \mathrm{w} / \mathrm{w}$ TAG's in nitrogen limiting medium, whereas free fatty acids and phospholipids (phosphatidylethanolamine 1.1, phosphatidylcholine 3.5, phosphatidylserine 3.3 and phosphatidylinositol $0.2 \% \mathrm{w} / \mathrm{w}$ ) only constituted a minor fraction of total lipid fraction. Dependent on the cultivation conditions, the fatty acid profile of $C$. oleaginosus TAG conventionally resembles that of cocoa butter $[60$, 61].

In liquid medium, temperature changes between 27 and $33{ }^{\circ} \mathrm{C}$ had no significant effect on the C. oleaginosus fatty acid (FA) spectrum [62]. By contrast, when grown at $15{ }^{\circ} \mathrm{C}$ on solid medium, the C. oleaginosus FA content shifts towards longer chain and higher unsaturated fatty acid (FA) content [63]. With regard to cultivation $\mathrm{pH}$, no differences were detected between cells grown at $\mathrm{pH}$ 6-7. By contrast, at $\mathrm{pH} 8$ and 9 concentrations of $\mathrm{C} 18: 0$ and C16:0 as well as C18:2 were increased respectively [52].

A significant change in the organisms TAG profile was detected depending on the carbon and nitrogen source used. In the presence of galactose or arabinose the C18:2 fatty acid pool was enhanced compared to the equivalent cultivations with glucose. However, cells grown on 
cellobiose, mannose and xylose did not show significant changes in the FA profile compared to glucose as a carbon source [44]. When utilizing complex biomass hydrolysates as growth media, the presence of inhibitory hydrolysis byproducts, such as furfural, PHB, syringaldehyde and vanillin shifted the FA spectrum away from C16:0, C18:0 and C18:1 towards C18:2 [44]. A similar effect was observed when using ammonia as nitrogen source as compared to nitrate [33]. Using VFAs as substrate decreased the amount of C18:2 and use of propionate as substrate made the generation of odd-numbered fatty acids, such as C17:0 or C17:1 possible [33], which are usually not found in yeast. Other methods for the modification of fatty acids have remained unexplored in C. oleaginosus: FA desaturase inhibitors were applied to modify the FA spectrum in Trichosporon cutaneum and oxygen levels were shown to affect FA spectra in a variety of oleaginous species [64]. Effects of different genetic modifications on FA distribution in C. oleaginosus are shown in Table 1.

\section{Mechanism and regulation of lipid accumulation}

Relevance of citrate for lipid biosynthesis has described early as part of the "standard model" of lipid accumulation by Ratledge [57]. While the basic mechanism for lipogenesis under nitrogen limitation has been elucidated in Y. lipolytica, there currently is no in-depth regulatory network defining and regulating lipid biosynthesis under nutrient limiting conditions. This applies even more so to the effects of phosphate- or sulfate limitation or the effect of acetic acid.

In this section available biochemical data is summarized, which comprehends molecular mechanisms for lipogenesis under $\mathrm{N}$-limiting growth conditions.

To that end, mitochondrial energy metabolism and management strongly interacts with cytosolic glycolysis reactions. Fatty acid synthesis requires AcCoA and malonyl-CoA (MaCoA). AMP-dependent isocitrate dehydrogenase (IDH) shows activity at very low AMP concentrations, as they are present during nitrogen limitation [65]. In that interaction, citrate is the master metabolite, which regulates intracellular energy (ATP) levels and lipid formation, which ultimately leads to growth stagnation. Citrate accumulates in the mitochondrion and is exported into the cytosol via a citrate/malate antiporter. ATP-citrate-lyase cleaves citrate to acetylCoA and oxaloacetate, which [64] is reintroduced into the citric acid cycle [57]. The primary reaction involves ATP-citrate-lyase, which cleaves citrate to acetyl-CoA and oxaloacetate, the latter of which is in turn reintroduced into the citric acid cycle [57]. The presence of ATP citrate lyase (ACL) is considered a defining feature of oil yeasts [66], but non-oleaginous strains with ACL have been described [67]. This suggests, that these organisms may have had the metabolic capacity to form lipids but may have lost this feature during the course of evolution. At present, the supply of NADH has not been fully elucidated, but both introduction of glucose-6-phosphate (by glucose-6-phosphate dehydrogenase, G6PDH) into the pentose phosphate pathway and shunting of pyruvate to oxaloacetate via malic enzyme are likely sources of reducing equivalents to sustain lipogenesis.

Kourist et al. [18] described a transcriptomic analysis of C. oleaginosus, comparing nitrogen limited medium containing glucose as carbon source with full complex medium. Amongst the most strongly upregulated genes were amino acid and ammonium transporters. Additionally, many proteases were upregulated to facilitate the recycling of nitrogen in non-essential peptides and proteins. Within the central nitrogen metabolism, equilibrium shifted away from ammonium and glutamine towards glutamate, which in turn is responsible for nitrogen supply to non-essential amino acids over transamination. The mitochondrial isocitrate exporter (Triol1|270035) was not upregulated and hence, the export of citrate to cytosol is possibly not a rate limiting step.

Supply of AcCoA and MaCoA for lipid synthesis was ensured by upregulation of ATP-citrate lyase (ACL) and AcCoA-carboxylase (ACC). These two constituents needed for the production of fatty acids are processed by fatty acid synthases (FAS1, FAS2), which in turn were upregulated as well [18]. NADPH demand for FA synthesis was most likely governed via G6PDH, as glucose6-phosphate dehydrogenase was upregulated, but malic enzyme (Triol1|326761) was not.

More recently, the role of cell signaling pathways in lipogenesis have been addressed for the first time by Bracharz et al. [68]. To that end, target of rapamycin complexes (TORCs) were identified as central, conserved integrators of stress signals. Involvement of TORC1 in response to nutrient stress was confirmed by rapamycin inhibition. TORC inhibition lead to an enhanced lipid content and a shift in fatty acid spectrum towards a pattern typical for nitrogen limitation. A homology based TORC signaling network assembled by the authors indicates, that cell signaling response to carbon depletion is conserved, whereas response to nitrogen limitation and autophagy are not.

\section{Process engineering}

Optimizing the fermentation process potentially offers the most rapid improvement in biomass yield and single cell lipid production. Therefore, this section elaborates on recently published data with a focus on process engineering in order to increase the productivity. 


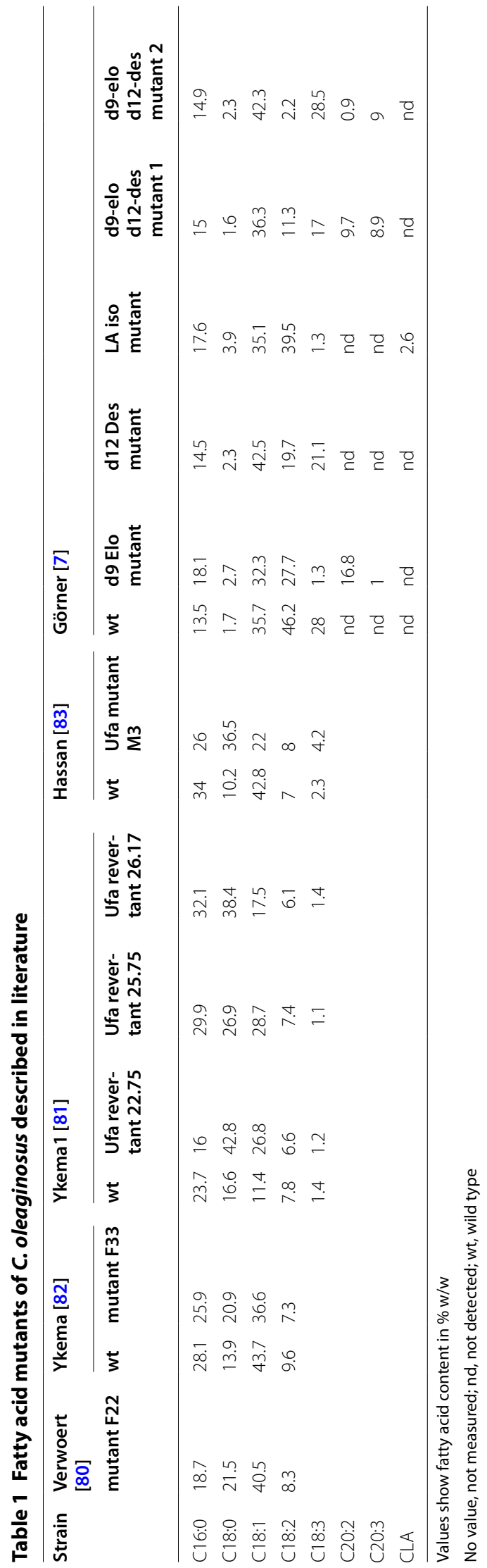




\section{Fermentation modes: chemostat, batch and fed batch}

Depending on the fermentation mode, substrate and conditions the $C$. oleaginosus biomass and lipid yield vary. As $C$. oleaginosus was isolated from a dairy farm initial reports focused on whey or whey permeate substrate, between $0.13 \mathrm{~g} / \mathrm{l}$ culture/hour for batch experiment and $0.38 \mathrm{~g} / \mathrm{l} / \mathrm{h}$ for chemostat cultivation could be achieved respectively (see Table 2 ). Highest lipid productivities were commonly between 0.4 and $0.6 \mathrm{~g} / \mathrm{l} / \mathrm{h}$, while $1 \mathrm{~g} / \mathrm{l} / \mathrm{h}$ was reported for chemostat cultivation with partial recycling [39] (see Table 3). Fermentations are commonly conducted between pH 5 and 6 (see substrate and growth preferences), while the reaction temperature was almost kept at $30{ }^{\circ} \mathrm{C}$. The average lipid yield over all fermentations was $16 \pm 8.4 \mathrm{~g} / 100 \mathrm{~g}$ substrate, while the stoichiometric maximum of the lipid yield was $33 \mathrm{~g}$ lipids $/ 100 \mathrm{~g}$ sugar [69]. Average lipid content was $39.3 \pm 14.4 \% \mathrm{~g} / \mathrm{g}$ with a maximum of $74 \% \mathrm{w} / \mathrm{w}$ and lipid production was at $14.3 \pm 11.8 \mathrm{~g} / \mathrm{l}$ with a maximum of $49 \mathrm{~g} / \mathrm{l}$. Average lipid production was higher at samples quantified by GC/FID $(17.1 \mathrm{~g} / \mathrm{l})$ in comparison to gravimetric measurements $(11.4 \mathrm{~g} / \mathrm{l})$, which was however not significant at $\mathrm{P}=0.05$. Single-stage continuous fermentation requires shorter average residence time than batch fermentation for sugar utilization [70] and showed an average higher lipid productivity. Aeration was commonly adjusted to $1 \mathrm{l} / \mathrm{l}$ culture/hour and insufficient supply of oxygen significantly decreased lipid yield and triglyceride content [71].

Fed-batch fermentations provide for the application of difficult carbon sources which are toxic in higher concentrations. Béligon et al. established a pH regulated feeding strategy utilizing acidic acid as carbon source coupled to the $\mathrm{pH}$. During the cultivation the consumption of acidic acid rises the $\mathrm{pH}$ which is compensated by the addition of acidic acid. With this strategy $80 \mathrm{~g} / \mathrm{l} \mathrm{DCW}$ was obtained within $60 \mathrm{~h}$ of fermentation containing 18\% lipids (g/g). With acidic acid as carbon source a maximum growth rate of $0.26 \mathrm{~g} / \mathrm{l} / \mathrm{h}$ could be achieved [72].

\section{Optimization of cultivation on different carbon sources}

Statistical methods such as design of experiments (DoE) can be suitable tools for the identification of interacting variables. Moreover, these methodologies enable predictions about fermentation yields. Using a Plackett-Burman design, Zheng et al. [73] tested the influence of different media supplements and cultivation parameters on C. oleaginosus CDW with $\mathrm{H}_{2}$ producing sludge as substrate. Acetate concentration had the strongest positive impact on CDW, followed by $\mathrm{pH}$, EDTA content and $\mathrm{pH}$. Increasing concentrations of ammonium chloride, magnesium sulfate and peptone had a negative effect. Significant dependent variables were picked for a central composite design (CCD), but as effects of single dependent variables are confounded with higher order effects in the screening, not all significant factors might have been included.

Using the CCD, mainly linear effects and two way interacting variables were identified. Towards that effect, ammonium chloride and acetate concentration were interacting with $\mathrm{pH}$, while the ammonium chloride concentration further interacted with acetate. Additionally, an interaction of the EDTA concentrations with magnesium sulfate was identified. However, as experimental confirmation showed a poor correlation with the predicted CDWs, the model may have to be further refined.

From the CCD, mainly linear effects and two way interactions were found: Effects of ammonium chloride and acetate concentration were interacting with $\mathrm{pH}$, ammonium chloride effect further interacted with acetate, and EDTA with magnesium sulfate. The model validity, however, is questionable, as experimental confirmation fitted poorly with the predicted CDWs.

The abundant availability of carbon rich food waste enables a never dwindling source for fermentative processes. Chi et al. established a combined process using food waste hydrolysate together with waste water for cultivation of different oleaginous yeast and microalgae strains [52]. In this approach, food waste hydrolysate was mixed with municipal waste water and used as fermentation medium. After 6 days of fermentation a biomass of $7.5 \mathrm{~g} / \mathrm{l}$ was produced containing $28.6 \%$ lipids.

Wastewater sludge occurs in large quantities in wastewater treatment plants and is rich in carbon, nitrogen and phosphorous. As renewable material, it is a promising nutrient source for fermentation of oleaginous yeasts [74]. However, a considerable disadvantage is the high nitrogen content preventing high lipid accumulation. By chemical complexation into struvite nitrogen can be removed from aqueous solutions. Unfortunately, Zhang et al. showed that formation of struvite is not sufficient for increasing the carbon to nitrogen ratio and for further increase of oil accumulation [75].

Beside the mentioned domestic waste source, macroalgae algae based biomass has numerous advantages. Macroalgae grows quickly and can be harvested several times per year compared terrestrial crop plants. In addition, on many coast regions macroalgae are accumulated at the beach and has to be removed. In a recent study, Xu et al. used extracts from dried kelp (Laminaria japocia) containing mainly mannitol mixed with VFAs as media for fermentation. In this work, a biomass of $3.6 \mathrm{~g} / \mathrm{l}$ was produced containing up to $48.3 \%$ of lipids [76].

Vega et al. optimized CDW of C. oleaginosus on banana juice [77] containing 25\% w/w sugars. A second order $\mathrm{CCD}$ was employed to find optimal $\mathrm{pH}$, concentration of substrate as well as optimal amounts of asparagine and 


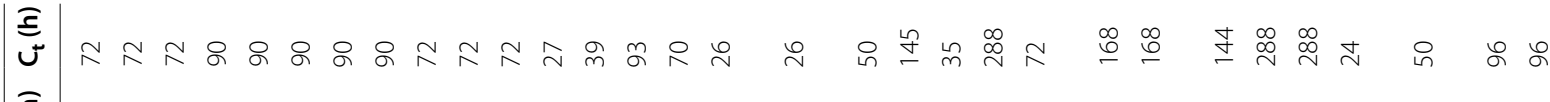

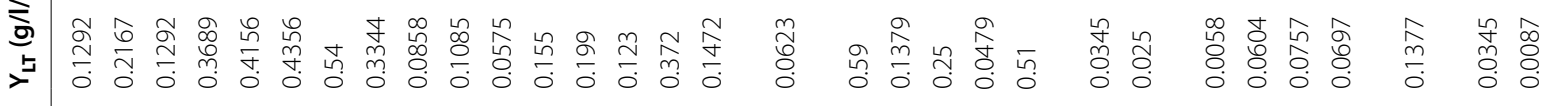

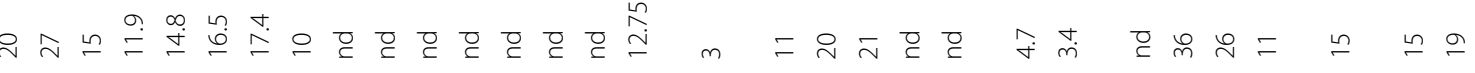

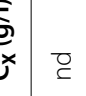

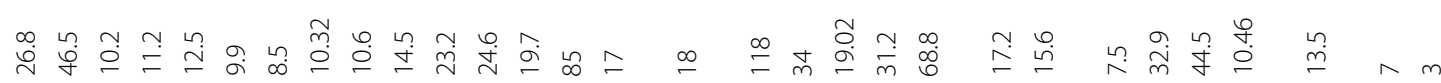

خ 氙 齐

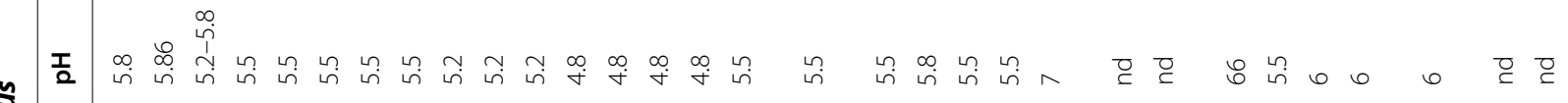

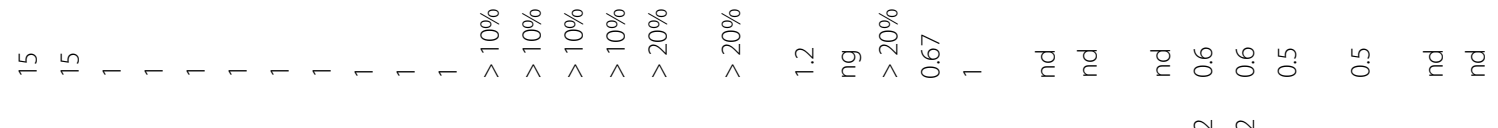

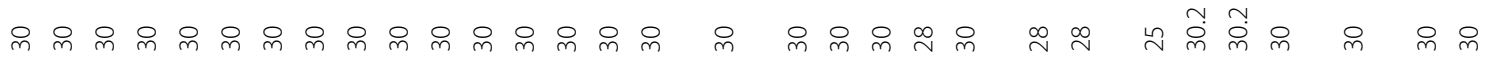

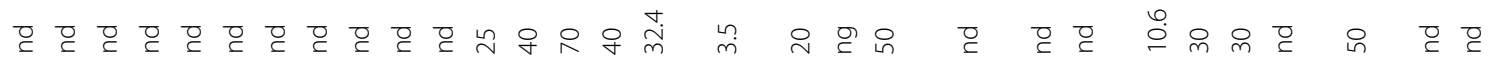

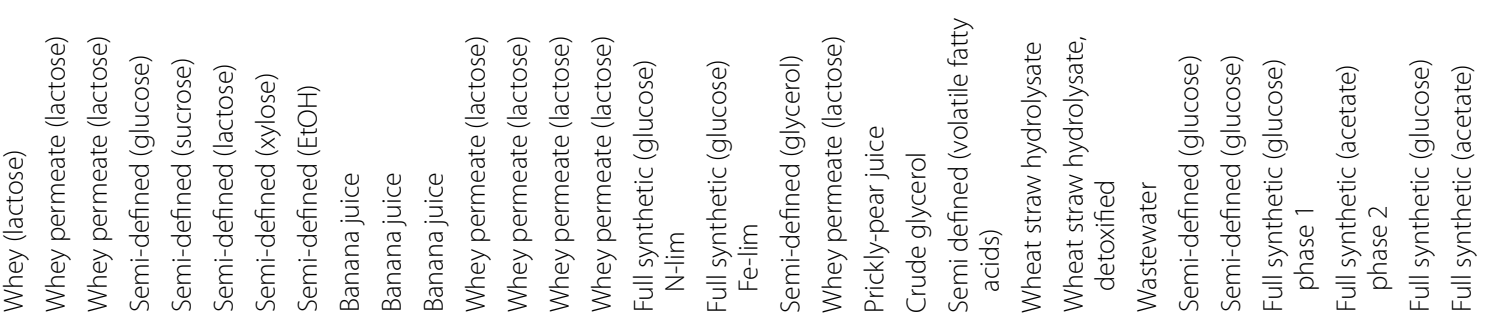

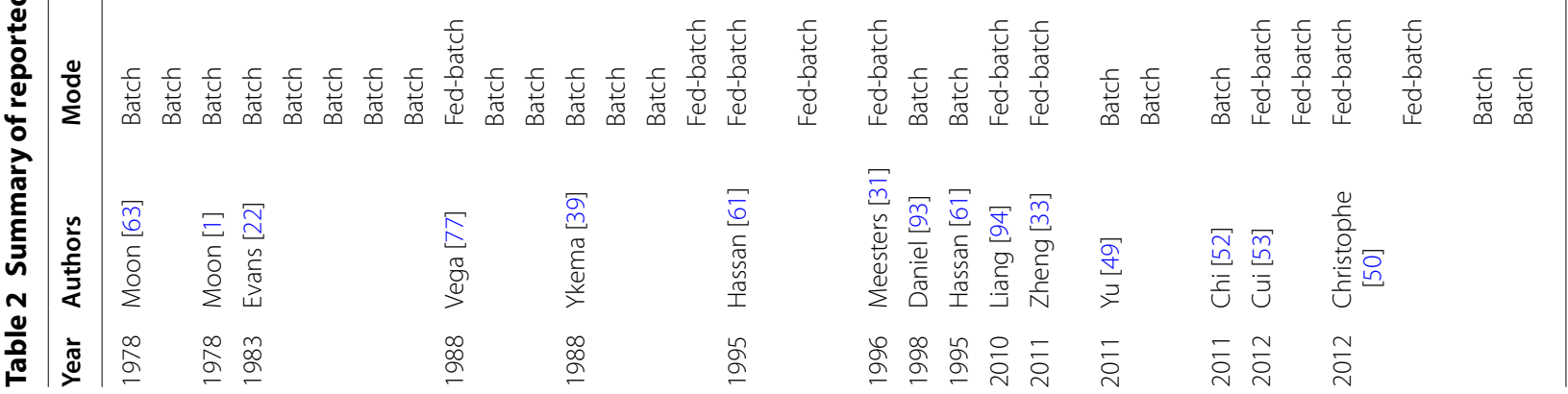




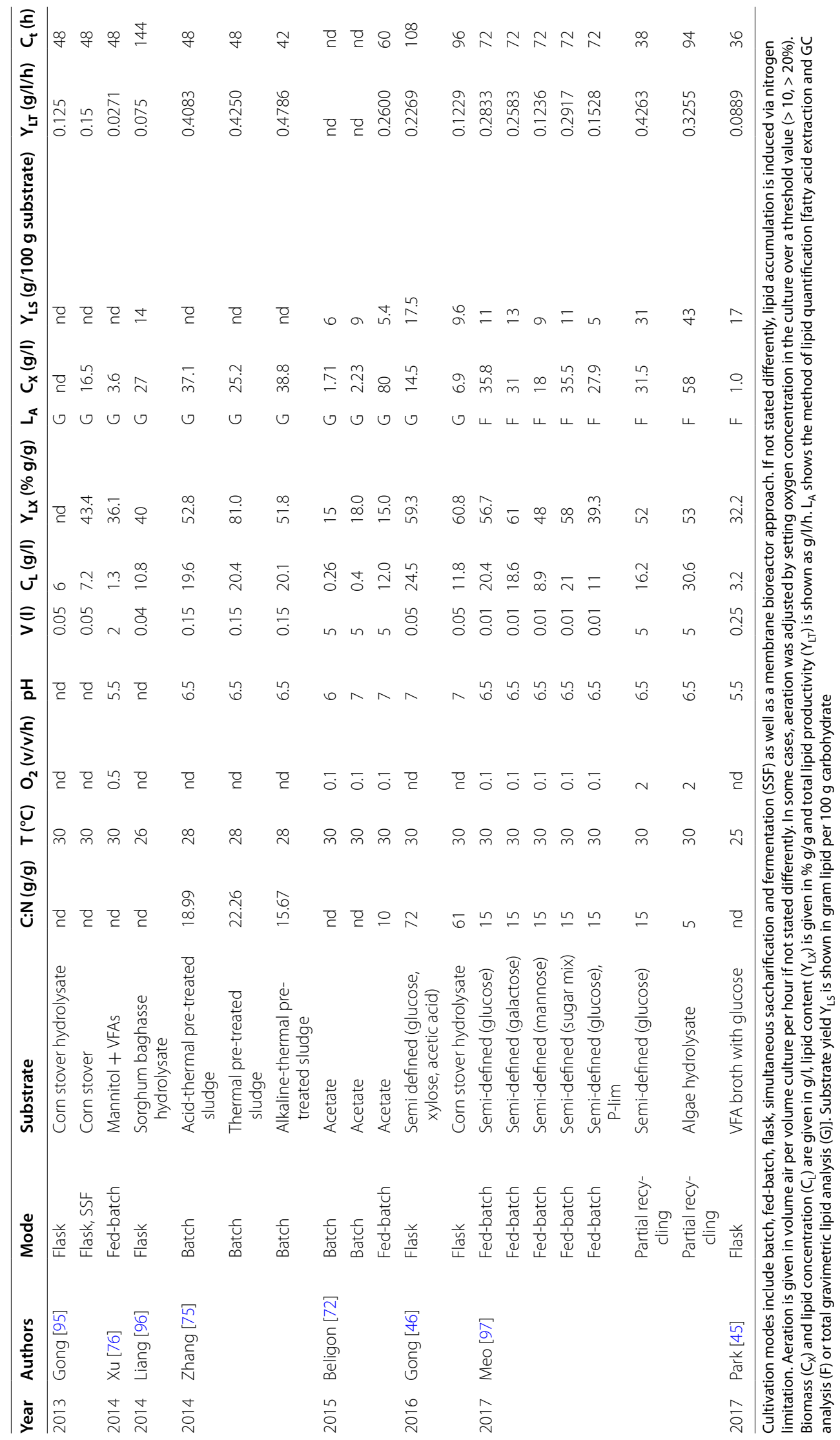




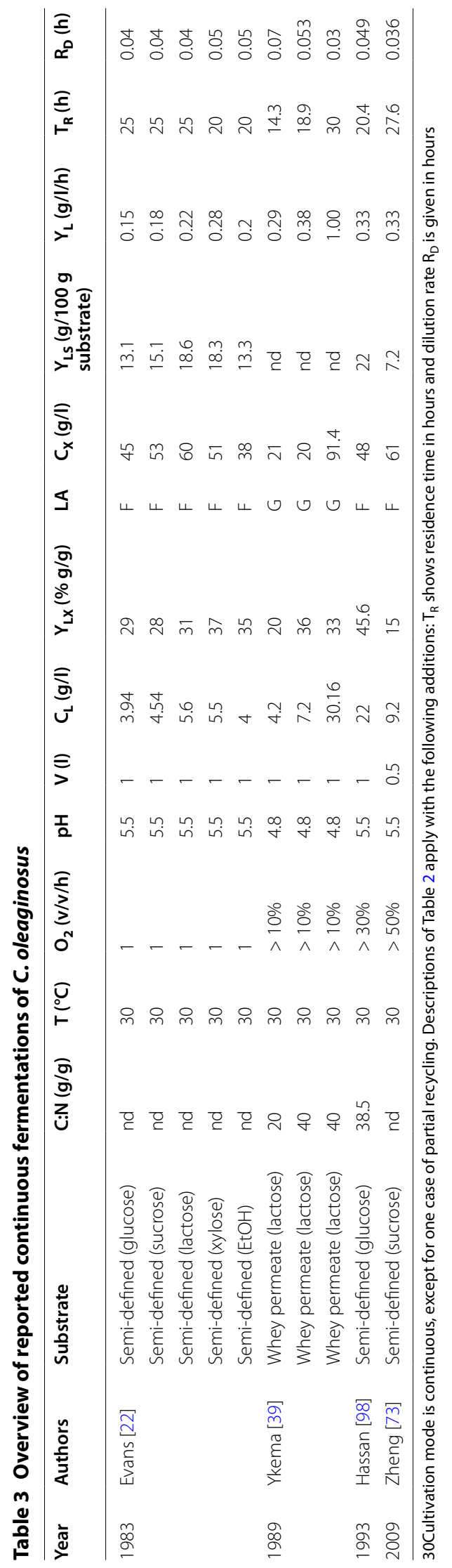


yeast extract supplementation. The factors initial $\mathrm{pH}$ (4.8-6.2) and asparagine concentration (15-255 mg/l) were found to be not significant. The factor yeast extract was only significant at juice concentrations under 19\% $\mathrm{v} / \mathrm{v}$, indicating a lack of nutrients in the juice. Optimum growth was achieved at $21 \% \mathrm{v} / \mathrm{v}$ juice $(5 \% \mathrm{w} / \mathrm{w}$ sugars), beyond which growth was impaired. In a two-level full factorial design, the method of sterilization, aeration plug and all previous variables were used as factors. By contrast, significantly higher yields were obtained with filter sterilization over autoclaving, and milk filters over dispo plugs. With a two factor second order CCD, an interaction effect between cultivation temperature and substrate concentrations were found: as juice concentration is increased, the optimal temperatures decreased.

Cui et al. used a Box-Behnken design to estimate effects of substrate (glycerol) concentration, $\mathrm{pH}$ and temperature on lipid productivity [53]. Both glycerol concentration $(10-30 \mathrm{~g} / \mathrm{l})$ and temperature $\left(27-33^{\circ} \mathrm{C}\right) \mathrm{had}$ more significant effects on biomass yield than $\mathrm{pH}(5-6)$. At $\mathrm{pH}$ 6, the temperature optimum was $30^{\circ} \mathrm{C}$ and optimal glycerol concentration was $20 \mathrm{~g} / \mathrm{l}$. For biomass, the significant factors were glycerol (negative), glycerol quadratic (negative), temperature (negative) and the interaction effect between temperature and $\mathrm{pH}$ (positive). For the lipid content, $\mathrm{pH}$ (positive effect), glycerol (negative effect) and glycerol (quadratic negative effect) were significant factors. The optimum was at $\mathrm{pH}$ 6, $20 \mathrm{~g} / \mathrm{l}$ glycerol and $30^{\circ} \mathrm{C}$.

In contrast to the former statistical approaches, Ykema et al. [2] applied a kinetic model to predict lipid production in a chemostat culture. Dependent on dilution rate and the $\mathrm{C}: \mathrm{N}$ ratio, the authors applied a semi-defined medium containing glucose as carbon substrate. The model was capable of predicting lipid production in dependence of $\mathrm{C}: \mathrm{N}$ ratio, but did not capture the dynamics of the carbohydrate content. Due to its scope, dependence of productivity was modeled only in dependence of few parameters and is therefore applicable only under these defined conditions. The same applies to Browns $[70,78]$ approach of separating growth into three phases and modeling nitrogen, non-lipid biomass, lactose and lipids using a set of differential equations. The cumulative data indicates, that process simulation are suitable tools to reduce the number of experiment and therefore enable accelerate substrate specific fermentation optimization.

\section{Genetic modification}

Genetic engineering is a route for improving and diversifying single cell lipid production.

To that end, chemical and biological approaches have been employed in C. oleaginosus.
While some biological methodologies have proven somewhat successful, the genetic modification of nonconventional yeasts remains challenging. The following section presents a spotlight on current approach to genetic engineering with a focus on C. oleaginosus.

\section{Random mutagenesis and spheroplast transformation} $N$-Methyl- $N^{\prime}$-nitro- $N^{\prime}$-nitrosoguanidine (MNNG) and acridine mustard (ICR-170) were suitable mutagens for generating amino acid auxotrophs of C. oleaginosus, whereas mutagenesis with ethyl methanesulfonate (EMS) and UV irradiation were less successful [79]. Fatty acid and unsaturated fatty acid auxotrophs were generated by Ykema et al. [79], mutants were created with a modified fatty acid distributions by intraspecific spheroplast fusion with methionine auxotrophs [80] (Table 1). Also revertants were characterized for their modified FA spectrum [81] and growth on whey permeate [82]. Fatty acid mutants were also generated by mutagenesis with EMS [83] and characterized (Table 1). As opposed to the description of Ochsner et al. [56] for strain Trichosporon dermatis (DSM70698), plasmid transformation into $C$. oleaginosus did not yield stable transformants (data not published).

\section{Agrobacterium-mediated transformation}

Görner et al. established a method for the stable integration of expression cassettes into the $C$. oleaginosus genome using Agrobacterium tumefaciens mediated transformation (ATMT) [7]. Codon optimized yellow fluorescent protein was expressed using the glyceraldehyde3-phosphate dehydrogenase (GDH) promoter and the respective GDH terminator from $C$. oleaginosus. Selection was done by also expressing hygromycin b phosphotransferase from $E$. coli using a truncated GDH promoter and terminator. Following this proof of concept, different bacterial enzymes for fatty acid modification were expressed to change the fatty acid spectrum of neutral and phospholipids (see Table 1). The approach suffered from the fact that the GDH appeared to be down-regulated under limiting conditions [18], thus limiting productivity of tailor made lipids in C. oleaginosus. So far, no other promoters for functional heterologous expression are described.

The reported data suggest, that $C$. oleaginosus is somewhat recalcitrant to genetic modification. Yarrowia lipolytica has been described as not favoring homologous recombination over non-homologous end joining [84], which appears to apply even more so to C. oleaginosus. Despite the absence of working plasmids for $C$. oleaginosus, there is some evidence of autosomal DNA fragments in the closely related strain $T$. cutaneum (DSM70698) [85]. Due to the absence of homology based 
methodologies which allow rapid genetic modifications at a specific locus, establishing CRISPR/CAS9 [86] or TALEN mediated [87] genetic transfer systems should be developed. In our hands this endeavor has proven to be a rather complex long term goals, due to the GC-rich nature of the $C$. oleaginosus genome, which complicates design of genetic constructs. Moreover, validation of genetic inserts via sequencing is complicated due to formation of secondary structures when target sequences are amplified by PCR.

\section{Conclusion}

The ability of C. oleaginosus to metabolize a broad spectrum monosaccharides and its resistance to fermentation inhibitors designate this organism as a preferred wholecell biocatalyst able to generate high levels of single cell oils from cost efficient biomass hydrolysates. The fermentation efficacy is enhanced as C. oleaginosus is able to simultaneously utilize sugar mixtures or VFAs. The utilization of acetate as carbon source further elevates the intracellular lipid content and circumvents the requirement for nutrient limitation to initiate lipogenesis. The effects of carbon on source lipid content and fatty acid composition is not reported uniformly throughout literature and appears to be interdependent on other fermentation variables, such as media composition and fermentation parameters. The same applies to the fatty acid spectrum, which strongly depends on carbon source, but nitrogen source and aeration also have significant effects.

A process of C. oleaginosus fermentation using whey permeate as substrate for production of triglycerides was patented as early as in 1980 [88]. However, since then, no further attempts at commercialization have been conducted. The majority of oil yeast research has been focused on the ascomycetous yeast $Y$. lipolytica, which resulted in a sizable body of literature with over 2400 articles. As the main metabolic paths leading to synthesis of triglycerides are highly conserved, many of the findings could be transferable to other oleaginous yeasts. However, bottlenecks for TAG production differ significantly between $Y$. lipolytica and $C$. oleaginosus: with respect to $C$. oleaginosus, the bottlenecks for lipid production may be manifested prior to TAG assembly. A primary issue may be issues with sugar uptake as described by Tchakouteu et al. [58]. Additionally, our recent data indicates that intracellular free fatty acid concentrations are low and that in contrast to Y. lipolytica, DGA overexpression did not provide for an increased TAG content (data not published). With all consideration, the natural lipid content of wild type Y. lipolytica (20 [89]-35\% w/w $[90,91])$ is relatively low compared to C. oleaginosus. However, $Y$. lipolytica's lipid content can be elevated to
$45 \% \mathrm{w} / \mathrm{w}$ [90] or even up to $90 \% \mathrm{w} / \mathrm{w}$ with sophisticated genetic engineering [92]. This also yielded in excess of 25 g/l lipids, a value which was achieved by cultivation of C. oleaginosus wildtype. Further, Y. lipolytica requires engineering for utilization of xylose and sucrose or to overcome strong diauxic effects [92]. Maximum growth rates for $Y$. lipolytica are comparable to C. oleaginosus [72]. All of these features are generically included in the wt genome of $C$. oleaginosus. Therefore it can be argued that further exploration of C. oleaginosus, despite challenges in its genetic accessibility, is worthwhile. Already as wild type, the strain displays high lipid content, fast growth to high biomass concentrations and a favorable fatty acid spectrum, which has been demonstrated to be modifiable. Further, development of specific genetic engineering tools would provide for development of C. oleaginosus as an industrial chassis for sustainable generation of single cell oils. Moreover, systems biology studies may be able to reveal the specific intracellular networks that govern lipid formation in the absence of nutrient limitation. Identification and genetic modification of selective cellular switching mechanisms may be a route to commercial single cell oil production using $C$. oleaginosus as a production host.

\section{Abbreviations}

ACC: AcCoA-carboxylase; AcCoA: acetyl-CoA; MaCoA: malonyl-CoA; ATMT: agrobacterium mediated transformation; ACL: ATP-citrate lyase; CDW: cell dry weight; CO: Cutaneotrichosporon oleaginosus; EMS: ethylmethanesulfonate; FA: fatty acid; GDH: glyceraldehyde-3-phosphate dehydrogenase; IDH: isocitrate dehyrogenase; LC: lipid content; MNNG: $N$-methyl- $N^{\prime}$-nitro$N^{\prime}$-nitrosoguanidine; NADPH: nicotinamide adenine dinucleotide phosphate; PHB: $p$-hydroxybenzaldehyde; TAG: triacylglycerides; VFA: volatile fatty acid.

\section{Authors' contributions}

FB conceived the review in its design. TB contributed information about phylogeny microbial and biochemical properties associated with the genus. The manuscript was drafted and finalized by all authors. All authors read and approved the final manuscript.

\section{Author details \\ ${ }^{1}$ Technische Universität München, Division of Industrial Biocatalysis, Lichten- bergstraße 4, 85748 Garching, Germany. ${ }^{2}$ Westerdijk Institute, Uppsalalaan 8,} 3584 CT Utrecht, The Netherlands.

\section{Acknowledgements}

Not applicable.

Competing interests

The authors declare that they have no competing interests.

\section{Availability of data and materials}

All data generated or analyzed during this study are included in this published article.

\section{Consent for publication \\ Not applicable.}

Ethics approval and consent to participate

Not applicable. 


\section{Funding}

This work was supported by the BMBF (German Federal Ministry of Education and Research, 03SF0446A).

\section{Publisher's Note}

Springer Nature remains neutral with regard to jurisdictional claims in published maps and institutional affiliations.

Received: 25 May 2017 Accepted: 14 October 2017 Published online: 25 October 2017

\section{References}

1. Moon NJ, Hammond EG, Glatz BA, American Public Health Association I, Atkin C, Witter LD, et al. Conversion of cheese whey and whey permeate to oil and single-cell protein. J Dairy Sci. 1978;61:1537-47.

2. Ykema A, Verbree EC, van Verseveld HW, Smit H. Mathematical modelling of lipid production by oleaginous yeasts in continuous cultures. Antonie Van Leeuwenhoek. 1986:52:491-506.

3. Ratledge C. Single cell oils - have they a biotechnological future? Trends Biotechnol. 1993;11:278-84

4. Moreton RS. Yeast lipid estimation by enzymatic and nuclear magnetic resonance methods. Appl Environ Microbiol. 1989:55:3009-11.

5. Gujjari P, Suh SOSO, Coumes K, Zhou JJJ. Characterization of oleaginous yeasts revealed two novel species: Trichosporon cacaoliposimilis sp. nov. and Trichosporon oleaginosus sp. nov. Mycologia. 2011;103:1110-8.

6. Yaguchi A, Rives D, Blenner M. New kids on the block: emerging oleaginous yeast of biotechnological importance. AIMS Microbiol. 2017:3:227-47

7. Görner C, Redai V, Bracharz F, Schrepfer P, Garbe D, Brück T. Genetic engineering and production of modified fatty acids by the non-conventional oleaginous yeast Trichosporon oleaginosus ATCC 20509. Green Chem. 2016:18:2037-46.

8. Liu X-Z, Wang Q-M, Göker M, Groenewald M, Kachalkin AV, Lumbsch HT, et al. Towards an integrated phylogenetic classification of the Tremellomycetes. Stud Mycol. 2015;81:85-147.

9. Sugita T, Takashima M, Ikeda R, Nakase T, Shinoda T. Phylogenetic and taxonomic heterogeneity of Cryptococcus humicolus by analysis of the sequences of the internal transcribed spacer regions and $18 \mathrm{~S}$ rDNA, and the phylogenetic relationships of C. humicolus, C. curvatus, and the genus Trichosporon. Microbiol Immunol. 2000;44:455-61.

10. Okoli I, Oyeka CA, Kwon-Chung KJ, Theelen B, Robert V, Groenewald JZ, et al. Cryptotrichosporon anacardii gen. nov., sp. nov., a new trichosporonoid capsulate basidiomycetous yeast from Nigeria that is able to form melanin on niger seed agar. FEMS Yeast Res. 2007;7:339-50.

11. Takashima M, Manabe R, Iwasaki W, Ohyama A, Ohkuma M, Sugita T. Selection of orthologous genes for construction of a highly resolved phylogenetic tree and clarification of the phylogeny of Trichosporonales species, vol. 10. Yurkov AM, editor. PLoS ONE. 2015; p. e0131217.

12. Kurtzman CP, Fell JW, Boekhout T. The yeasts: a taxonomic study. Amsterdam: Elsevier; 2010.

13. Morrow CA, Fraser JA. Sexual reproduction and dimorphism in the pathogenic basidiomycetes. FEMS Yeast Res. 2009;9:161-77.

14. Liu X-Z, Wang Q-M, Theelen B, Groenewald M, Bai F-Y, Boekhout T. Phylogeny of tremellomycetous yeasts and related dimorphic and filamentous basidiomycetes reconstructed from multiple gene sequence analyses. Stud Mycol. 2015:81:1-26.

15. Depree J, Emerson GW, Sullivan PA. The cell wall of the oleaginous yeast Trichosporon cutaneum. J Gen Microbiol. 1993;139:2123-33.

16. Ykema A, Bakels RHA, Verwoert IIGS, Smit H, van Verseveld HW. Growth yield, maintenance requirements, and lipid formation in the oleaginous yeast Apiotrichum curvatum. Biotechnol Bioeng. 1989;34:1268-76.

17. Van Bodegom P. Microbial maintenance: a critical review on its quantification. Microb Ecol. 2007:53:513-23.

18. Kourist R, Bracharz F, Lorenzen J, Kracht ON, Chovatia M, Daum C, et al. Genomics and transcriptomics analyses of the oil-accumulating basidiomycete yeast Trichosporon oleaginosus: insights into substrate utilization and alternative evolutionary trajectories of fungal mating systems. MBio. 2015;6:e00918.

19. Glatz BA, Floetenmeyer MD, Hammond EG. Fermentation of bananas and other food wastes to produce microbial lipid. J Food Prot. 1985;48:574-7.

20. Chang Y-H, Chang K-S, Lee C-F, Hsu C-L, Huang C-W, Jang H-D. Microbial lipid production by oleaginous yeast Cryptococcus sp. in the batch cultures using corncob hydrolysate as carbon source. Biomass Bioenergy. 2015;72:95-103.

21. Rattray JBM. Biotechnology and the fats and oils industry — an overview. Soc: J Am Oil Chem; 1984.

22. Evans CT, Ratledge C. A comparison of the oleaginous yeast, Candida curvata, grown on different carbon sources in continuous and batch culture. Lipids. 1983;18:623-9.

23. Wu S, Hu C, Zhao X, Zhao ZK. Production of lipid from N-acetylglucosamine by Cryptococcus curvatus. Eur J Lipid Sci Technol. 2010;112:727-33.

24. Zhang G, French WT, Hernandez R, Hall J, Sparks D, Holmes WE. Microbial lipid production as biodiesel feedstock from $\mathrm{N}$-acetylglucosamine by oleaginous microorganisms. J Chem Technol Biotechnol. 2011;86:642-50.

25. West M, Emerson GW, Sullivan PA. Purification and properties of two lactose hydrolases from Trichosporon cutaneum. J Gen Microbiol. 1990;136:1483-90.

26. Liang Y, Jarosz K, Wardlow AT, Zhang J, Cui Y. Lipid production by Cryp tococcus curvatus on hydrolysates derived from corn fiber and sweet sorghum bagasse following dilute acid pretreatment. Appl Biochem Biotechnol. 2014;173:2086-98.

27. Meo A. Lipidherstellung aus verdünnten Zuckergemischen mit Trichosporon oleaginosus. München: Technische Universität München; 2016.

28. Knoshaug EP, Franden MA, Stambuk BU, Zhang M, Singh A. Utilization and transport of L-arabinose by non-Saccharomyces yeasts. Cellulose. 2009; $16: 729-41$

29. Smolke CD. The metabolic pathway engineering handbook : fundamentals. CRC Press/Taylor \& Francis; 2010

30. Evans CT, Ratledge C. Induction of xylulose-5-phosphate phosphoketolase in a variety of yeasts grown ond-xylose: the key to efficient xylose metabolism. Arch Microbiol. 1984;139:48-52.

31. Meesters PAEP, Huijberts GNM, Eggink G. High-cell-density cultivation of the lipid accumulating yeast Cryptococcus curvatus using glycerol as a carbon source. Appl Microbiol Biotechnol. 1996:45:575-9.

32. lassonova DR. Lipid synthesis and encapsulation by Cryptococcus curvatus. 2009

33. Zheng Y, Chi Z, Ahring BK, Chen S. Oleaginous yeast Cryptococcus curvatus for biofuel production: Ammonia's effect. Biomass Bioenerg. 2012;37:114-21.

34. Behrend T, Guiého E, Tredick J, Phaff HJ. DNA base composition and DNA relatedness among species of Trichosporon Behrend. Antonie Van Leeuwenhoek. 1984;50:17-32.

35. Wu S. Microbial lipid production by Rhodosporidium toruloides under sulfate-limited conditions.

36. Wu S, Hu C, Jin G, Zhao X, Zhao ZK. Phosphate-limitation mediated lipid production by Rhodosporidium toruloides. Bioresour Technol. 2010;101:6124-9.

37. Li Y, Zhao Z, Bai F. High-density cultivation of oleaginous yeast Rhodosporidium toruloides $Y 4$ in fed-batch culture. Enzyme Microb Technol. 2007:41:312-7.

38. Park W-S, Murphy PA, Glatz BA. Lipid metabolism and cell composition of the oleaginous yeast Apiotrichum curvatum grown at different carbon to nitrogen ratios. Can J Microbiol. 1990;36:318-26.

39. Ykema A, Verbree EC, Kater MM, Smit H. Optimization of lipid production in the oleaginous yeast Apiotrichum curvatum in wheypermeate. Appl Microbiol Biotechnol. 1988;29:211-8.

40. Li T, Li C-T, Butler K, Hays SG, Guarnieri MT, Oyler GA, et al. Mimicking lichens: incorporation of yeast strains together with sucrose-secreting cyanobacteria improves survival, growth, ROS removal, and lipid production in a stable mutualistic co-culture production platform. Biotechnol Biofuels BioMed Central. 2017:10:55.

41. Yang $X$, Jin G, Gong Z, Shen H, Song Y, Bai F, et al. Simultaneous utilization of glucose and mannose from spent yeast cell mass for lipid production by Lipomyces starkeyi. Bioresour Technol. 2014;158:383-7.

42. $Y u X$, Zheng $Y$, Xiong $X$, Chen S. Co-utilization of glucose, xylose and cellobiose by the oleaginous yeast Cryptococcus curvatus. Biomass Bioenerg. 2014;71:340-9. 
43. Fakas S, Papanikolaou S, Batsos A, Galiotou-Panayotou M, Mallouchos A, Aggelis $\mathrm{G}$. Evaluating renewable carbon sources as substrates for single cell oil production by Cunninghamella echinulata and Mortierella isabellina. Biomass Bioenerg. 2009;33:573-80.

44. Yu X, Zeng J, Zheng Y, Chen S. Effect of lignocellulose degradation products on microbial biomass and lipid production by the oleaginous yeast Cryptococcus curvatus. Process Biochem. 2014;49:457-65.

45. Park GW, Chang HN, Jung K, Seo C, Kim Y-C, Choi JH, et al. Production of microbial lipid by Cryptococcus curvatus on rice straw hydrolysates. Process Biochem. 2017;56:147-53.

46. Gong Z, Zhou W, Shen H, Yang Z, Wang G, Zuo Z, et al. Co-fermentation of acetate and sugars facilitating microbial lipid production on acetaterich biomass hydrolysates. Bioresour Technol. 2016;207:102-8.

47. Larsson S, Palmqvist E, Hahn-Hägerdal B, Tengborg C, Stenberg K, Zacch $\mathrm{G}$, et al. The generation of fermentation inhibitors during dilute acid hydrolysis of softwood. Enzyme Microb Technol. 1999;24:151-9.

48. Ruan Z. Developing novel biological processes to convert lignocellulose into lipid based biofuel. East Lansing: Michigan State University; 2014.

49. Yu X, Zheng Y, Dorgan KM, Chen S. Oil production by oleaginous yeasts using the hydrolysate from pretreatment of wheat straw with dilute sulfuric acid. Bioresour Technol. 2011;102:6134-40.

50. Christophe G, Deo JL, Kumar V, Nouaille R, Fontanille P, Larroche C. Production of oils from acetic acid by the oleaginous yeast Cryptococcus curvatus. Appl Biochem Biotechnol. 2012;167:1270-9.

51. Palmqvist $E$, Hahn-Hägerdal B. Fermentation of lignocellulosic hydrolysates. II: inhibitors and mechanisms of inhibition. Bioresour Technol. 2000;74:25-33.

52. Chi Z, Zheng Y, Ma J, Chen S. Oleaginous yeast Cryptococcus curvatus culture with dark fermentation hydrogen production effluent as feedstock for microbial lipid production. Int J Hydrog Energy. 2011;36:9542-50.

53. Cui Y, Blackburn JW, Liang Y. Fermentation optimization for the production of lipid by Cryptococcus curvatus: use of response surface methodology. Biomass Bioenerg. 2012;47:410-7.

54. Fleet $\mathrm{GH}$. Composition and structure of yeast cell walls. New York: Springer; 1985. p. 24-56.

55. Sullivan PA, Yin CY, Molloy C, Templeton MD, Shepherd MG. An analysis of the metabolism and cell wall composition of Candida albicans during germ-tube formation. Can J Microbiol. 1983;29:1514-25.

56. Ochsner UA, Glumoff V, Kälin M, Fiechter A, Reiser J. Genetic transformation of auxotrophic mutants of the filamentous yeast Trichosporon cutaneum using homologous and heterologous marker genes. Yeast. 1991;7:513-24.

57. Evans CT, Ratledge $C$. The physiological significance of citric acid in the control of metabolism in lipid-accumulating yeasts. Biotechnol Genet Eng Rev. 1985;3:349-76.

58. Tchakouteu SS, Chatzifragkou A, Kalantzi O, Koutinas AA, Aggelis G, Papanikolaou S. Oleaginous yeast Cryptococcus curvatus exhibits interplay between biosynthesis of intracellular sugars and lipids. Eur J Lipid Sci Technol. 2015;117:657-72.

59. Meeuwse P. Production of fungal lipids Kinetic modeling and process design. Wageningen; 2011.

60. Wei Y, Siewers V, Nielsen J. Cocoa butter-like lipid production ability of non-oleaginous and oleaginous yeasts under nitrogen-limited culture conditions. Appl Microbiol Biotechnol. 2017;101:3577-85.

61. Hassan M, Blanc PJ, Pareilleux A, Goma G. Production of cocoa butter equivalents from prickly-pear juice fermentation by an unsaturated fatty acid auxotroph of Cryptococcus curvatus grown in batch culture. Process Biochem. 1995:30:629-34

62. Moreton RS. Single cell oil. Harlow: Longman Scientific \& Technical; 1988.

63. Moon NJ, Hammond EG. Oil production by fermentation of lactose and the effect of temperature on the fatty acid composition1. J Am Oil Chem Soc. 1978;55:683-8.

64. Moreton RS. Modification of fatty acid composition of lipid accumulating yeasts with cyclopropene fatty acid desaturase inhibitors. Appl Microbiol Biotechnol. 1985;22:41-5.

65. Ratledge C. Regulation of lipid accumulation in oleaginous micro-organisms. Biochem Soc Trans. 2002;30:1047-50.

66. Park BG, Kim M, Kim J, Yoo H, Kim B-G. Systems biology for understanding and engineering of heterotrophic oleaginous microorganisms. Biotechnol J. 2016;:12:1600104
67. Boulton C, Ratledge C. Correlation of lipid accumulation in yeasts with possession of ATP: citrate lyase. J Gen Microbiol. 1981;127:169-76.

68. Bracharz F, Redai V, Bach K, Qoura F, BrückT. The effects of TORC signal interference on lipogenesis in the oleaginous yeast Trichosporon oleaginosus. BMC Biotechnol. 2017;17:27.

69. Ratledge C, Cohen Z. Microbial and algal oils: do they have a future for biodiesel or as commodity oils? Lipid Technol. 2008;20:155-60.

70. Brown BD. A kinetic study on the oleaginous yeast, Candda curvata D. $1984 ; 175$.

71. Capusoni C, Rodighiero V, Cucchetti D, Galafassi S, Bianchi D, Franzosi G, et al. Characterization of lipid accumulation and lipidome analysis in the oleaginous yeasts Rhodosporidium azoricum and Trichosporon oleaginosus. Bioresour Technol. 2017;238:281-9.

72. Beligon V, Poughon L, Christophe G, Lebert A, Larroche C, Fontanille P. Improvement and modeling of culture parameters to enhance biomass and lipid production by the oleaginous yeast Cryptococcus curvatus grown on acetate. Bioresour Technol. 2015;192:582-91.

73. Zheng Y, Chi Z, Chen S. Biodiesel and biohydrogen co-production with treatment of high solid food waste final report biodiesel and biohydrogen co-production with treatment of high solid food waste ecology publication number 09-07-065. 2009.

74. Seo Yh, Lee Ig, Han J. Cultivation and lipid production of yeast Cryptococcus curvatus using pretreated waste active sludge supernatant. Bioresour Technol. 2013;135:304-8.

75. Zhang X, Yan S, Tyagi RD, Surampalli RY, Valéro JR. Lipid production from Trichosporon oleaginosus cultivated with pre-treated secondary wastewater sludge. Fuel. 2014;134:274-82

76. Xu X, Kim JY, Oh YR, Park JM. Production of biodiesel from carbon sources of macroalgae, Laminaria japonica. Bioresour Technol. 2014;169:455-61.

77. Vega EZ, Glatz BA, Hammond EG. Optimization of banana juice fermentation for the production of microbial oil. Appl Environ Microbiol. 1988;54:748-52.

78. Douglas Brown B, Hsu KH, Hammond EG, Glatz BA. A relationship between growth and lipid accumulation in Candida curvata D. J Ferment Bioeng. 1989;68:344-52.

79. Ykema A, Verbree EC, Nijkamp HJJ, Smit H. Isolation and characterization of fatty acid auxotrophs from the oleaginous yeast Apiotrichum curvatum. Appl Microbiol Biotechnol. 1989;32:76-84

80. Verwoert IGSIGS, Ykema A, Valkenburg JC, Verbree EC, John H, Nijkamp $\mathrm{J}$, et al. Modification of the fatty-acid composition in lipids of the oleaginous yeast Apiotrichum curvatum by intraspecific spheroplast fusion. Appl Microbiol Biotechnol. 1989;32:327-33.

81. Ykema A, Verbree EC, Verwoert IIGS, van der Linden KH, Nijkamp HJJ, Smit $\mathrm{H}$. Lipid production of revertants of Ufa mutants from the oleaginous yeast Apiotrichum curvatum. Appl Microbiol Biotechnol. 1990;33:176-82.

82. Ykema A, Kater MM, Smit H. Lipid production in wheypermeate by an unsaturated fatty acid mutant of the oleaginous yeast Apiotrichum curvatum. Biotechnol Lett. 1989;11:477-82.

83. Hassan M, Blanc PJ, Pareilleux A, Goma G. Selection of fatty acid auxotrophs from the oleaginous yeast Cryptococcus curvatus and production of cocoa butter equivalents in batch culture. Biotechnol Lett. 1994;16:819-24.

84. Kretzschmar A, Otto C, Holz M, Werner S, Hübner L, Barth G. Increased homologous integration frequency in Yarrowia lipolytica strains defective in non-homologous end-joining. Curr Genet. 2013:59:63-72.

85. Glumoff V, Käppeli O, Fiechter A, Reiser J. Genetic transformation of the filamentous yeast, Trichosporon cutaneum, using dominant selection markers. Gene. 1989;84:311-8.

86. Jacobs JZ, Ciccaglione KM, Tournier V, Zaratiegui M. Implementation of the CRISPR-Cas9 system in fission yeast. Nat Commun. 2014;5:5344.

87. Bedell VM, Wang Y, Campbell JM, Poshusta TL, Starker CG, Krug RG, et al. In vivo genome editing using a high-efficiency TALEN system. Nature. 2012;491:114-8.

88. Moon NJ, Hammond EG. Process for converting whey permeate to oilcontaining yeast. United States: United States Patent; 1980.

89. Xue Z, Sharpe PL, Hong S-P, Yadav NS, Xie D, Short DR, et al. Production of omega-3 eicosapentaenoic acid by metabolic engineering of Yarrowia lipolytica. Nat Biotechnol. 2013:31:734-40.

90. Wang G-Y, Zhang Y, Chi Z, Liu G-L, Wang Z-P, Chi Z-M. Role of pyruvate carboxylase in accumulation of intracellular lipid of the oleaginous yeast Yarrowia lipolytica ACA-DC 50109 
91. Ledesma-Amaro R, Nicaud JM. Yarrowia lipolytica as a biotechnological chassis to produce usual and unusual fatty acids. Prog Lipid Res. 2016;61:40-50

92. Blazeck J, Hill A, Jamoussi M, Pan A, Miller J, Alper HS. Metabolic engineering of Yarrowia lipolytica for itaconic acid production. Metab Eng. 2015;32:66-73.

93. Daniel H-J, Reuss M, Syldatk C. Production of sophorolipids in high concentration from deproteinized whey and rapeseed oil in a two stage fed batch process using Candida bombicola ATCC 22214 and Cryptococcus curvatus ATCC 20509. Biotechnol Lett. 1998;20:1153-6.

94. Liang Y, Cui Y, Trushenski J, Blackburn JW. Converting crude glycerol derived from yellow grease to lipids through yeast fermentation. Bioresour Technol. 2010;101:7581-6.
95. Gong Z, Shen H, Wang Q, Yang X, Xie H, Zhao ZK. Efficient conversion of biomass into lipids by using the simultaneous saccharification and enhanced lipid production process. Biotechnol Biofuels. 2013;6:36.

96. Liang Y, Tang T, Siddaramu T, Choudhary R, Umagiliyage AL. Lipid production from sweet sorghum bagasse through yeast fermentation. Renew Energy. 2012;40:130-6.

97. Meo A, Priebe XL, Weuster-Botz D. Lipid production with Trichosporon oleaginosus in a membrane bioreactor using microalgae hydrolysate. J Biotechnol. 2017;241:1-10.

98. Hassan M, Blanc P, Granger L-M, Pareilleux A, Goma G. Lipid production by an unsaturated fatty acid auxotroph of the oleaginous yeast Apiotrichum curvatum grown in single-stage continuous culture. Appl Microbiol Biotechnol. 1993:40:483-8.

\section{Submit your next manuscript to BioMed Central and we will help you at every step:}

- We accept pre-submission inquiries

- Our selector tool helps you to find the most relevant journal

- We provide round the clock customer support

- Convenient online submission

- Thorough peer review

- Inclusion in PubMed and all major indexing services

- Maximum visibility for your research

Submit your manuscript at www biomedcentral com/submit 